tions. M. Maikoff presented a report of the Committee appointed to discuss the subject of a thorough historical and ethnographical exploration of Bulgaria. Col. Lebedeff presented a sketch of the orography of the Balkan peninsula, according to the last geodetical and topographical operations in Bulgaria by officers of the Russian General Staff. The orography of much of the Balkan peninsula has been pretty well studied, a complete trigonometrical report having been completed, and a relief-map on a large scale, like that of the Cauca us, is now in preparation.

A LIVELy controversy having arisen between the cantons of Geneva and Vaud as to the importance of the dam erected at Geneva with reference to the level of Lake Leman, the Fournal de Genive has published during the past month a series of papers by $M . H$. de Saussure on Lake Leman, the changes of its level, the destructive action of its waves, and generally on its physical conditions. These papers have a great scientific value. We notice also several papers on the same subject published by the Gazette de Lausanne in answer to M. de Saussure's articles.

WE notice an interesting note by MM. Polonsky and Meyer on that part of the eastern shore of the Caspian which is described as Tentiak-sor, and is a former lake now transformed into a series of lagoons separated by muddy spaces. Its origin is explained by M. Meyer by a falling of level of the Caspian. Prof, Lenz having made an incision in a rock at Baku in 1830 , the subsequent measurements showed that the level stood-in $1837,1^{\circ} 6$ feet lower; in $1847,0^{\circ} 7$ feet higher ; in $1848, r^{\prime} 3$ foot; in $185^{2}, 2^{\circ} 9$ feet; in $1853,2^{\circ} 5$ feet; and in $186^{\circ} \mathrm{r}, 3^{\circ} 9$ feet lower than in 1837 . This circumstance would be in complete accord with the general diminution of water in all Asiatic lakes, and would perfectly explain a multitude of important physico-geographical phenomena.

HEFT v. of Petermann's Mittheilungen begins with an article by C. Marten, on the Inhabited Part of Chili South of the River Valdiviz; Dr. Behm gives some collected information on the gold-fields of Wassa, on the Upper Ankobra, north from the Gold Coast ; Dr. Junker narrates his journey through the Libyan Desert to the Natron Lakes; and Herr Bernhard von Struve writes on the history of trade-routes in East Siberia. The Ergänzungheft No. 6I consists of a physico-geographical account of the Portuguese Mountain group, the Serra da Estrella, with special reference to its forestal conditions, by Herr J. Rivoli. In the June number Dr. A. Regel gives an interesting account of a visit he made last year to Turfan, in Central Asia. Dr. Emin-Bey describes his journey from Dufilé to Fatiko in December, 1878, and January, 1879. Herr Lindemann gives some statistical information on the forests of Bavaria in connection with a map of the Bavarian Spessart. Herr E. R. Flegel gives a detaile 3 narrative of his journey in the Henry Venn in July and August last year, up the Binué, from Gandé to Djen.

THE Fapan Mail states that development in the trade between Japan and Corea is confidently anticipated in consequence of the opening of the port of Gensan. The Japanese residents at Fusan, in the south of the Corean peninsula, are said already to exceed 14,000 in number, and we may therefore hope that we shall soon have more detailed information regarding the interior of the country than has hitherto been accessible.

THE Melbourne correspondent of the Colonies and India states that Mr. White, of the Reed Beds, near Adelaide, has fitted out the schooner Elsea, and has left on an exploring cruise to New Guinea for the purpose of making natural history investigations, which are expected to occupy two years.

IN the introduction to his lately published report on the trade and commerce of the Caucasian Provinces, Mr. Lyall, H.B.M.'s Consul for Tiflis and Poti, gives a succinct account of the geographical features of this region, accompanied by remarks oa its climate, resources, communications, \&c. Though the information is not perbaps entirely new, it is interesting to be able to take in at a glance so much relating to a tract of country which is daily becoming more and more important.

Col. Flatters, who had left Wargla on March $\mathrm{I}_{5}$ with a column of 100 men for an exploration in connection with the intended Trans-Algerian Railway, returned to Wargla on May 20 , after having travelled 600 miles in the direction of Raof, without meeting any opposition from the natives. He intends to resume his explorations in the months of September or October, in another direction. He was unable to discover the Ighorghor Wed, which is marked on every map.
From August 5 to Io next the French Geographical Society: will meet at Nancy for their triennial meeting.

WE have received Parts 12 to $I 6$, each containing three mape, of the new edition of Stieler's " Hand-Atlas."

THE Kussian Department of Estates has just published an interesting atlas of six maps, representing the distribution of soils in Russia. The atlas is accompanied by a text by M. Dokoutchaeff. The maps were drawn five years ago by $\mathrm{M}$. Tchaslavsky, who has studied this subject during many years.

\section{THE ROYAL OBSERVATORY}

THE following are the points that seem to us of most interest in the Report of the Astronomer-Royal to the Board of Visitors at their recent Visitation :-

The Admiralty have decided not to proceed with the erection of a new library at present, though the space has been cleared, admitting of the erection of a building fifty by twenty feet. The Astronomer-Royal proposes to erect here a room of one story, but with galleries at mid-height, so that there would never be need to use a ladder. Among other changes occurring in this clearance, he has removed the electrometer mast (a source of some expense and some danger); the perfect success of Sir William Thomson's electrometer rendering all further apparatus for the same purpose unnecessary. With regard to the library the Report states that no change has been made in plan, but in some departments the number of books has increased rapidly. "Fundamental astronomy advances slowly, magnetism is almost stationary, geodesy progresses, photography and spectroscopy increase very fast, and meteorology the most rapidly of all. The Transactions of foreign Academies increase in number. This is owing, I imanine, to the general scientific activity, both of Academicians and of private men of science, in most foreign countries, and to the facilities given for transmission, by the courtesy of publishers and by the extension of book post."

Under the head of Astronomical Observations, the Report says: "The : un, moon, planets, and fundamental stars are the regular subjects of observation on the meridian, special attention being devoted to the moon, which is also observed at every available opportunity with the altazimuth. Other stars are observed from a working catalogue of about 2,500 stars, with which good progress has been made in the past year, though a large number of stars still remain for observation. A bont I, roo stars were observed in 1879." Between May 20, 1879, and May 9, I880, the following observations were made :-With the transit circle 4,164 transits, the separate limbs being connected as separate observations ; 3,953 circle-observations; with the reflexzenith tube, 23 pairs of observation of $\gamma$ Draconis ; with the altazimuth, 7I3 azimuths of the moon and stars and 352 zenith distances of the moon. A set of micrometer-measures of the outer satellite of Mars and several sets of measures of the satellites of Saturn, were obtained last autumn with the south-east equatorial, and a few drawings of Mars and Jupiter were made near the time of opposition. A remarkable proof of the exceptionally bad weather of last summer is found in the fact that in July it caused the lo:s of a whole month's observations of the sun.

Under the heading of Spectroscopic and Photographic Observations we find the following statement:- "The sun's chromosphere has been examined on thirty-seven days during the period to which this Report refers, and on thirty-four days prominences were seen. Whenever practicable, the appearance of the prominences as seen on each of the chromospheric lines has been recorded, and on four days a detailed examination of the whole spectrum of the chromosphere was made at twentyfour points of the sun's limb. Three sun-spots have been examined with reference to the broadening of lines in their spectra, and fifteen photographs bave been taken of the spectra of three sun spots. As regards the spectroscopic determination of starmotions, I 13 measures have been made of the displacement of the $F$ line in the spectra of 29 stars, 44 of the $b_{1}$ line in 19 stars, and 6 of the $b_{4}$ line in 3 stars. Of these $5 \mathrm{I}$ stars 21 had not previously been examined. In the case of three of the stars a dispersive power equivalent to that given by fifteen prisms of $60^{\circ}$ was used. The stars are taken from a working list of $I_{50}$ stars, which may eventually be extended to include all stars down to the fourth magnitude, and it is expected that in course of time the motions of about 300 stars may be spectroscopically determined. The spectra of comets $c$ (Swift's) and $d$ (Palisa's) 
1879, and of the red spot on Jupiter, have been examined, but no certain results were obtained. Between 1879, May 20, and 1880, May 9, photographs of the sun were taken on 145 days, and of these 270 have been selected for preservation. The photographs show a complete absence of spots on 64 days out of 145, whilst in the preceding year there was a similar absence of spots on I2I days out of 150 . The epoch of minimum appears to have occurred about the beginning of 1879 , and since last October the outbreak of spots has been very marked." Various spectroscopic and photographic results, it is stated, have been communicated to the Committee on Solar Physics, with whom, the Report states, the Observatory is in friendly communication.

Under Magnetical and Meteorological Instruments we are told that the Thomson electrometer is in excellent order. "In the warm weather of summer, and in winter when much artificial heat is used in the basement, the photographs have been unsatis. factory, but we are endeavouring to remedy this by cutting of all communication with air from the basement. In the winter the register was frequently interrupted by the freezing of the water in the exit-pipe. A basin (with cesspool) has been recently constructed to carry off the water discharged from this pipe. The action of the photographic barometer appears to have been improved by the slight changes mentioned in the last Report, and small movements are in many cases excellently shown. A new pressure.plate with springs has been applied by Mr. Browning to Osler's anemometer, and it is proposed to make such modification as will give a scale extending to $50 \mathrm{lbs}$. pressure on the square foot. Other parts of the instrument have also been renewed. An arrangement for slow motion of the barrel, which was much wanted in adjusting the recording paper, has been fitted to Robinson's anemometer. It is in contemplation to alter the photographic cylinders of the magnetometers, barometer, thermometers, and earth-currents apparatus, so as to make the time-scales of all the magnetical and meteorological instruments the same."

Some interesting information is given under the head of Reduction of Magnetical and Meteorological Observations.

The following are given as the principal results for magnetic elements in the year 1879 :-

Approximate mean westerly declination ... $\quad \ldots \quad \ldots \quad \ldots$

Mean horizontal force ... $18^{\circ} 40^{\prime}$ $\left\{\begin{array}{l}3.911 \text { (in English units). } \\ 1.803 \text { (in Metric units). }\end{array}\right.$

Mean dip... $\int 6736$ " 5 (by $9 \cdot$ inch needles). $\{73654$ (by 6-inch needles). 673747 (by 3 -inch needles).

"On the application of the Committee on Solar Physics, the separate daily values of the diurnal range of magnetic declination for the years 1848 to 1858 have been supplied to Prof. Balfour Stewart."

The Report goes on to say:- "The Visitors at their last meeting suggested the advantage of prepariny a digested account of the magnetical results obtained at the Royal Observatory from 1841 to 1876 , similar in some respects to the account of meteorological results recently published. A beginning was made by preparing the monthly means of diurnal inequality in force and direction through the whole period, and exhibiting their combination in curves. It is known to the Visitors that, in two communications to the Royal Society, I have exhibited numerically and in curves the means of these monthly results (yearly means through all months, and monthly means through all years) as far as the year 1863. In 1864 observations were interrupted by the work in progress for the magnetic basement, so that the reductions now to be made commence with 1865 . The monthly results through the whole period being taken as before, the next step, for obtaining exhibitions which the eye and the mind could easily command, was to collect the monthly conclusions into a limited number of groups of years. On inspecting the monthly curves in detail there was no hesitation in fixing upon the following:-First group, 1865 to 1868 ; second group, 1869 to 1872 ; third group, 1873 to 1876 . In each of these, as before, yearly means are taken through all months, and monthly means through all years. The curves in the second group are strikingly larger than those in the first and third; the linear dimensions of the curves of 1870 are fully $\frac{5}{3}$ of those of 1876 in the east-and-west direction, and fully $\frac{7}{3}$ in the north-andsouth direction. In the study of the forms of the individual curves; their relations to the hour, the month, the year; their connection with solar or meteorological facts; the conjectural physico-mechanical causes by which they are produced; there is much to occupy the mind. I regret that, though in contemplation of these curves I have remarked some singular (but imperfect) laws, I have not been able to pursue them. The heavy load on the Observatory, and the limited means (in the present year) of supporting it, will in part explain this."

Under "Chronometers, Time-signals," \&c., we are told that during the period to which the Report refers "the error of the Westminster Clock exceeded Is. on I20 days; on 32 of these it was between $2 \mathrm{~s}$, and $35_{\circ}$, on 4 days between $3 \mathrm{~s}$. and $4 \mathrm{~s}$., and on I day it exceeded $4 \mathrm{~s}$.

"I have reason to believe," the Astronomer-Royal states, " that the use of the time-signals, originating at the Royal Observatory, and distributed automatically from the General Post Office, is becoming more and more extensive, and it seems probable that the same system may be adopted by foreign nations. Very lately an examination of our instruments was made on the part of another country, with the view of establishing something similar in one of their maritime cities; and it was intimated that Greenwich time would probably be used as standard. The establishment of time-balls, \&c., at foreign ports is increasing."

With regard to the progress of the operations in connection with the transit of Venus, 1874 , it is stated that permission was given by the Treasury to Major Tupman last September to devote his time to the work till the end of June, 1880. The result is (taking the stations or station-groups in the order which the Astronomer-Royal proposes for publication): the observations and calculations of the Sandwich or Hawaiian group are completed; those of the Egyptian group nearly finished; those of Rodriguez completed; those of Kerguelen nearly finished; and also those (which unfortunately are less im. prrtant) of New Zealand. "In January of the present year I received through the Admiralty the notification of the Treasury that the printing of the observations and calculations might proceed. It has gone on rather languidly; but I have before me in type $128 \mathrm{pag} \cdot \mathrm{s}$, including the text and the greater portion of the tabular part of the Honolulu work. I propose to take steps for urging on this printing."

"With regard to the transit of 1882 ," the Report goes on to state, "I have lately placed a memorandum before the Royal Astronomical Society. From the facility with which the requirements for geographical position are satisfied, and from the rapid and accurate communication of time now given by electric telegraph, the observation of this transit will be comparatively easy and inexpensive. I have attached greater importance than I did formerly $t$ ) the elevation of the sun. For the four principal phases (ingress accelerated, and retarded; egress accelerated, and retarded) I propose to rely mainly on: Ist, the Cape Colony; 2nd, the shores of Canada and the United States, Bermuda, and the West India Islands; 3 rd, the same as the 2nd; 4th, the eastern shore of Australia, or New Zealand in preference if telegraph communication be made. I remark that it is highly desirable that steps be taken now for determining by telegraph the longitude of some point of Australia."

The Astronomer-Royal makes the following statement in reference to his own lunar theory:- "The general principle of this is : to adopt for correction the best existing theory; to compute with the severest accuracy the numerical values of the terms produced geometrically by the tabular coefficients, and also the terms really due to the forces which produce them; and to remove the differences between these by corrections of the tabular coefficients, for which corrections proper factors are prepared. It was a special object with me to avoid the use of powers of $m$ (a symbol well known to lunar theorists), and to give easy means of computing, not new absolute values, but corrections of existing numerical coefficients (a principle which I have adopted extensively in other branches of astronomy), and also of computing the effect of small external disturbances or small changes of force. Both these are obtained by my process. The heaviest part of the work is the severe computation to which I have alluded, and this is done entirely by junior computers. The calculations had been carried out in every part to the accuracy of $10^{-7}$; but for securing the degree of accuracy which I proposed it was found necessary to extend many parts to $10^{-8}$, and some to $10^{-9}$. This has caused a very great addition to the labour, but the work has advanced well, and will, I trust, be finished ere long. While waiting for this, which is to give the correction to every coefficient of the ordinary lunar theory, I am employing myself partly in rearranging the whole work for 
publication, and in putting calculations in order for that correction of coefficients ; and partly on three ramifications or supplements of the theory relating to the effect of the earth's oblate. ness, the effect of change of position of the ecliptic plane, and the effect of change of excentricity of the earth's orbit, and lunar acceleration. The last of these I have completed to my satisfaction, requiring only an examination of the external factor; the two others are progressing. The Admiralty have assisted me, on estimates, with a moderate grant (of amount named by myself), but much of the expense has been private."

The Report concludes as follows:- "After the details into which I have entered as applying to the present state of the Observatory, and after the remarks whici I have made in the two reports last preceding on the question of reduction of printing (which at some fitting time I would willingly again present to the consideration of the Visitors), and the note in the last report on the increase of annual expense, I have only to place before the Visitors, but for no immediate expression of opinion, the impression which frequently weighs upon me as to the ulterior organisation of the Observatory. The determination of places of stars, sun, moon, and planets, was handed down to me from my predecessors; it has in various ways been much extended. The magnetic and meteorological observations (the first originating with myself, the second partly with the movement introduced by the Royal Society and partly by myself) constituted a distinct branch of science, having this property in common with the original astronomical work, that it is incessant and regular. The much later introduction of photographic and spectroscopic astronomy, established at the instance of the Board of Visitors, and carried on with vigour and regularity, has created a third department. All these departments appear at present to be working efficiently and well. But I can easily imagine circumstances which would interfere materially with the successful continuation in one place of this triplicate series of observations. Though I think this possibility of partial failure worthy the contemplation of the Visitors, yet I do not see any necessity for action of any kind at the present time."

\section{INTERCOLONIAL METEOROLOGICAL CONFERENCE AT SYDNEY}

A METEOROLOGICAL Conference was held at Sydney in November last, the representatives of the different Colonies being Messrs. James Hector for New Zealand, Charles Todd for South Australia, R. L. J. Ellery for Victoria, and H. C. Russell for New South Wales, the last-named gentleman being chairman. The most cordial unanimity characterised the meeting, which lasted from the IIth to the $\mathrm{r} 4 \mathrm{th}$ of the montb, and the resolutions arrived at with a view to secure united action in their meterrological investigations and uniformity in the methods and times of observing and forms of publication augur well for the future of meteorology in the Australian Colonies. The whole question of weather telegrams was under anxious consideration. The system in present operation embraces only the Colonies of South Australia, Victoria, New South Wales, and Queensland, but a resolution was passed declaring it desirable to secure the co-operation of the Governments of Western Australia, Tasmania, and New Zealand in the system of inter-colonial weather telegrams. The facts pointed out by Mr. Todd as to the great regularity observed by the atmospheric disturbances in pursuing a course from west to east, and the statement by Dr. Hector that early notices could be sent from Queensland of the origin and progress of the dangerous and suddenly occurring cyclones that cross the northern part of New Zealand, sufficiently attest the practicability of the system of weather warnings and their practical value. For instance, the "great storm which wrecked the Dandenong in September, 1876 , could have been telegraphed in sufficient time to have prevented the great loss of property which took place at the different ports along the coast of New South Wales. We have the greatest pleasure in noting a deliverance by the Conference to the effect that weather telegrams and forecasts shall in all cases depend upon the observations used for general meteorological and climatological statistics. Much emphasis was laid on the establishment of high-level stations with a more special view to the investigation of the winds; and the Conference recommended that there be established in each of the Colonies, upon a high mountain peak, a meteorological observatory for the special study of winds and other meteorological phenomena, the most desirable positions being Mount Lofty, in South Australia, 2,500 feet high ; Kian- dra, in New South Wales, 4,60o feet; Mount Wellington, in Tasmania, 4,000 feet; Mount Macedon, in Victoria, 3,500 feet; and in New Zealand, Tauhara Taupo, 4,600 feet, and Mount Herbert, 4,000 feet. We hope that the Governments of the different Colonies will vote the small sums which are required to carry out the resolutions of the Conference, the giving practical effect to which will certainly confer substantial advantages on commercial, shipping, and other interests, and contribute materially to a more satisfactory development of the meteorology of this important part of the globe.

\section{UNIVERSITY AND EDUCATIONAL INTELLIGENCE}

Cambridge.-At St. John's College Prof. Liveing has been elected to a foundation fellowship, and Dr. Kennedy, Prof, Sylvester, F.R.S., and Prof. Churchill Babington were elected honorary fellows of the society.

The following awards for proficiency in natural science have been made at St. John's College :-A Foundation Scholarship to Samways; a Proper Sizarship to Love, and Exhibitions to Hart (already scholar), Weldon, Edmunds, Love, T. Roberts. Fleming was awarded one of the Hughes Prizes, given to the two most distinguished third-year students in any branch of study, and a Wright's Prize, with augmentation of the year's emoluments to rool. The Open Exhibition was awarded at Easter to Scott-Taylor (City Middle-class School, Cowper Street), and a second Exhibition to Clementson (Newcastleunder-Iyme).

We understand that Mr. W. J. Lewis has been appointed to perform the duties of Professor of Mineralogy at Cambridge until the close of the year, the period to which the election to the chair has been postponed by the University Commissioners.

\section{SCIENTIFIC SERIALS}

Zeitschrift fïr wissenschaflliche Zoologie, May.-Prof. Zygmunt Kahane, on the anatomy of Tenia perfoliata, Göze, as a contribution to the lnowledge of the Cestoids, with a plate and a woodcut. The actual facts recorded in the paper were originally laid before the Academy of Sciences of Krakau in May, 1878, and were afterwards published in a somewhat altered form, in the Polish tongue, in their Proceedings. The investigations were carried on during the summer and autumn of 1877 in the Zoological Institute at Leipzig, under the supervision of Prof. Leuckart. The history of the species is treated at length, and the paper extends over seventy-seven pages.--Dr. G. Haller, Contribution to a knowledge of the Tyroglyphida and their allies, with three plates : describes a new species of Listrophorus (L. pagenstecheri): On the genus Homopus, Koch. It is not an independent genus, but the forms are only the larval stages of Dermacarus, which is described as a new parasitic genus; Ty'ogly. phus megninii is described as a new species. There is a sketch of a delineation of the internal anatomy of Tyroglyphus and Dermacarus, and of the egg in these genera.-Prof. Ludwig Stieda, on the structure and development of the Bursa fabricii, with five woodcuts.--Dr. Hubert Ludwig, on the primary sand canal in the Crinoids, with some remarks on the comparative anatomy of the Echinoderms in general, with two plates.-Dr. H. Ludwig, new contributions to the anatomy of the Ophiuroids, with three plates.

Fournal de Physique, May.-Measurement of the electromotive forces of batteries and electromotive forces of contact of metals, by M. Pellat.-Study of polariser-prisms used in photometric observations, by $M$. Crova,-On the illumination of electrodes, by M. Colley.-On a new capillary electrometer, by M. Debrun. - To determine with the aid of an articulated system the conjugate points of an optical system, by M. Elie.

Archives des Sciences Physiques et Naturelles, May 15.-On the earths of samarskite, by M. Marignac.-Researches on the condensation of gases on the surface of glass, by M. Chappuis. - The Siemens machine and its application to transmission of force, by $M$. Achard.-Specific heat, latent heat of fusion, and point of fusion of various refractory metals, by M. Violle.

The Reale Istituto Lombardo di Scienze e Lettere, Rendiconti, vol. xiii., fasc. iv, and v.-The phylloxera considered in rural economy, by S. Cantoni.-Geological notes on the basin of Lake d'Orta, by Dr. Parona.--Iealth and beneficence; their mutual relations, byDr. Zucchi. 